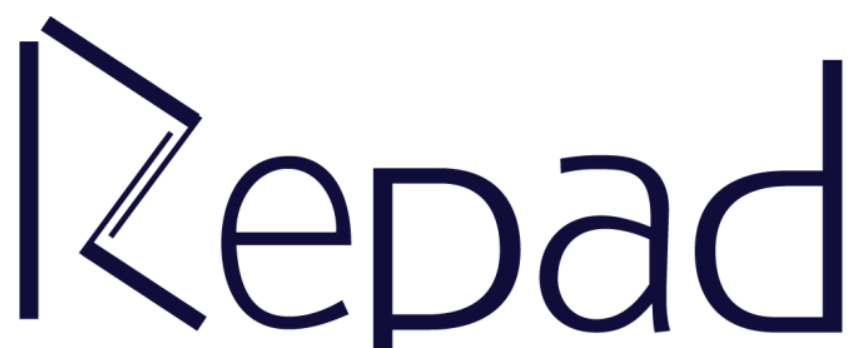

Vol. 2, n. 3, Dezembro/2018

Revista Estudos e

Pesquisas em Administração

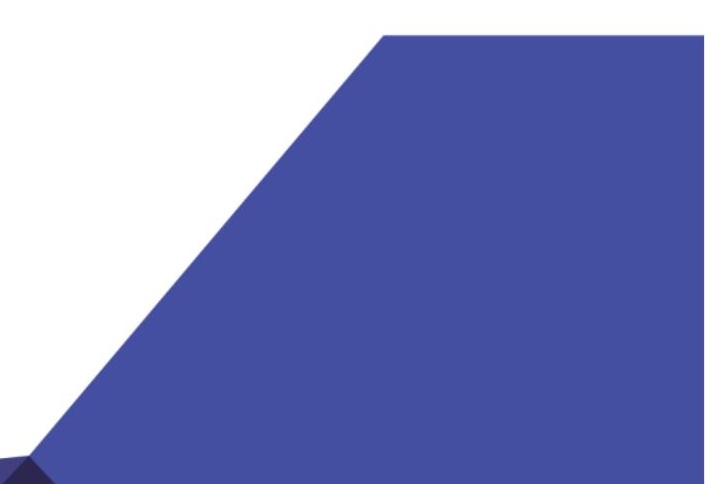




\title{
A PERCEPÇÃO DOS CLIENTES DE UMA EMPRESA DE GRANDE PORTE QUANTO À USABILIDADE DO APLICATIVO DE CARTÃO NO MUNICÍPIO DE RONDONÓPOLIS-MT
}

\author{
Vanessa da Silva Ossuna \\ Universidade Federal de Mato Grosso \\ https://orcid.org/0000-0002-8998-6202 \\ Maurício Alves Rodrigues Pugas \\ Universidade Federal de Mato Grosso \\ https://orcid.org/0000-0003-3704-435X
}

\section{RESUMO}

Ao entender a experiência dos clientes pode-se levar a tomar decisões mais assertivas de forma a interagir da melhor forma possível com o público almejado. As pessoas buscam facilidade e rapidez no uso dos aplicativos de modo que os acessos devam ser simples e intuitivos. O objetivo geral desta pesquisa é o de identificar e analisar a experiência dos clientes quanto a usabilidade do aplicativo do cartão de compras em uma empresa do setor varejista no município de Rondonópolis - MT. Esta pesquisa é qualitativa, e para a coleta de dados foram utilizados um questionário eletrônico aplicado em 110 clientes, e a utilização da técnica netnográfica para a categorização da página do Facebook da empresa. Após a análise dos dados pode concluir que as dificuldades encontradas pelos clientes são determinadas principalmente pela lentidão ao acessar o aplicativo de cartão e a necessidade de demonstração de como utilizar o aplicativo de forma rápida e simples atendendo assim as expectativas de ambos ao obterem processos operacionais de forma eficiente e objetiva.

Palavras-chave: Experiência dos usuários. Usabilidade. Aplicativos.

\section{THE PERCEPTION OF CUSTOMERS OF A LARGE COMPANY REGARDING THE USABILITY OF THE CARD APPLICATION IN THE MUNICIPALITY OF RONDONÓPOLIS-MT}

\begin{abstract}
Understanding customer experience can lead to more assertive decisions in order to better interact with the intended audience. People are looking for ease and speed in the use of applications so that access must be simple and intuitive. The general objective of this research is to identify and analyze the customers' experience regarding the usability of the shopping cart application in a retail company in the municipality of Rondonópolis - MT. This research is qualitative, and for the data collection we used an electronic questionnaire applied in 110 clients, and the use of the netnographic technique for the categorization of the company Facebook page. After analyzing the data, it can be concluded that the difficulties encountered by customers are mainly determined by the slow access to the card application and the need to demonstrate how to use the application quickly and easily, thus meeting the expectations of both to obtain operational processes of efficiently and objectively.
\end{abstract}

Keywords: User experience. Usability. Applications. 


\section{INTRODUÇÃO}

O estudo da experiência do usuário traz importantes contribuições para as organizações, como a identificação de lacunas nos serviços e produtos para atender positivamente o conhecimento dos usuários por meio do aperfeiçoamento e a tomada de decisões assertivas. Por isso o tema desta pesquisa é importante para ampliar o conhecimento sobre a vivência dos usuários, em razão das mudanças constantes juntamente com os avanços tecnológicos que ocorrem no mundo. Esta ferramenta, se for bem implantada na organização, poderá ser utilizada para entender melhor os usuários, de modo, a integrá-los no seu negócio e inovar a partir até mesmo das percepções encontradas.

Esta pesquisa teve como objetivo geral identificar e analisar a experiência dos clientes quanto a usabilidade do aplicativo do cartão de compras em uma empresa do setor varejista no município de Rondonópolis - MT, baseando-se na experiência dos usuários em relação ao aplicativo de cartão da empresa Beta, com o intuito de contribuir para que haja melhores tomadas de decisões, principalmente no meio digital, que está sendo cada vez mais difundido pelo mercado, como um dos canais que facilitam o relacionamento do consumidor com a organização, além de conduzir a vantagem competitiva organizacional.

Os objetivos específicos para atender a finalidade desta pesquisa são: a) Identificar as principais dificuldades e suas possíveis razões; b) Analisar a experiência dos clientes em relação ao aplicativo de cartão; e c) Propor um tutorial de utilização do aplicativo do cartão para clientes da empresa "Beta".

Foram observados que alguns problemas enfrentados pela organização em relação ao aplicativo refere-se a dificuldades por parte dos clientes na utilização do aplicativo de Cartão. Assim, ao buscar por meio da literatura sobre o tema experiência dos clientes compreende-se que ao analisar a experiência dos mesmos poderá implicar em melhorias e maior probabilidade de satisfação dos clientes, assim como auxiliar em melhores tomadas de decisões, além de relacionar a empresa com o cliente de forma eficaz ao maximizar a melhoria de suas operações.

O tipo de pesquisa adotada é o estudo de caso, em que o objeto é uma empresa de grande porte do setor varejista de Rondonópolis - MT. No entanto a empresa não autorizou a divulgação de seu nome nesta pesquisa, sendo assim, a empresa é denominada como "Beta", com o intuito de que sua imagem não seja exposta.

Foi aplicado um questionário eletrônico contendo perguntas fechadas e abertas para que pudesse responder aos objetivos propostos neste trabalho.

No tratamento e análise dos dados foi utilizado as respostas dos 110 clientes, além da categorização dos dados encontrados na página do Facebook da empresa local por meio da técnica netnográfica.

Nos tópicos seguintes são abordados o referencial teórico, os procedimentos metodológicos, o tratamento e análise dos resultados, e a conclusão desta pesquisa.

\section{REFERENCIAL TEÓRICO}

A base teórica desta pesquisa foi subdividida em três tópicos: aplicativos em relação cliente e empresa, usabilidade e satisfação dos clientes, e por fim a experiência do usuário no meio tecnológico. 


\section{RELACIONAMENTO CLIENTE E EMPRESA COM O USO DE APLICATIVOS}

Os telefones celulares desempenham forte influência entre a população mundial, e cresce cada vez mais com o passar dos anos, desde os mais simples até os mais sofisticados (ZONATO, 2014).

Conforme Siqueira e Christino (2017, p. 3), "Em conjunto com a evolução da internet, o avanço da rede de telefonia e de dispositivos móveis em todo o mundo propiciou mudanças no consumo, relacionamento das pessoas e empresas". Assim as empresas necessitam acompanhar os avanços tecnológicos para que não estagnem e percam participação do mercado para os seus concorrentes.

As organizações que não se adequam ao alto crescimento da tecnologia e constante evolução estão se submetendo ao próprio declínio, assim como Amaral (2012, p.10), ressalta:

As organizações responsáveis pela provisão de produtos e serviços de informação devem estar preocupadas em manter um relacionamento em duas vias com os seus públicos, em especial com os seus usuários, considerados clientes e/ou consumidores, para conhecer seus perfis de interesse pelos produtos e serviços de informação a serem oferecidos (AMARAL, 2012, p.10).

Uma das formas das empresas se aproximarem dos seus clientes é por meio da tecnologia, como por exemplo, ao utilizarem a forma de promoverem seus serviços a disponibilização de aplicativos.

Zonato (2014, pp. 18-19) define os aplicativos, como: "softwares, pagos ou gratuitos, que podem ser instalados nos aparelhos móveis, ampliando suas funcionalidades". Estes softwares, disseminaram rapidamente no mercado global por meio da internet e de forma bastante acessível ao público, como podemos observar principalmente nos dias atuais. As organizações, também têm visto este meio de comunicação na aproximação dos clientes e indutor de vantagem competitiva.

É a partir do marketing que se pode identificar e satisfazer as necessidades humanas e sociais, ou seja, o suprimento das necessidades de forma lucrativa (KOTLER; KELLER, 2012)

As empresas que estão atualizadas com o mercado, objetivam cada vez mais estarem próximas dos seus clientes. Assim os meios de comunicação que estão em suas mãos, como as mídias sociais são uma ótima forma de se conectarem de forma rápida e prática a qualquer momento e em qualquer lugar (CIRIBELI; PAIVA, 2011).

As mídias sociais também facilitam as relações entre os usuários, evitando conflitos entre os clientes e a empresa. Assim, a organização conseguirá aproximar-se do seu públicoalvo, atendendo as necessidades dos mesmos, não se esquecendo de monitorar precisamente as mídias adotadas pela organização para que possam estabelecer ações preventivas e rápidas para lidar com os problemas (CIRIBELI; PAIVA, 2011).

$\mathrm{O}$ uso da tecnologia frequentemente gera a experiência que está relacionado com a expectativa de desempenho (ED), que é o grau em que o indivíduo tem sobre a utilidade percebida sobre o produto ou serviço, e a expectativa de esforço (EE), que é o grau de facilidade do uso. Assim, são influenciadas pelas atitudes dos usuários e as suas interferências principalmente em relação as tecnologias móveis (GOMES; FARIAS, 2017). "A atitude positiva em relação ao uso de aplicativos poderá contribuir para maior difusão dessas tecnologias e ampliação de novos modelos de negócios direcionados ao mercado de desenvolvimento de aplicativos" (GOMES; FARIAS, 2017, p.88) 
No tópico seguinte, são abordados o conteúdo em relação a satisfação e a usabilidade dos clientes com a interface no meio tecnológico.

\section{USABILIDADE E SATISFAÇÃO DOS CLIENTES}

A satisfação é uma das melhores trajetórias para o reconhecimento de uma marca no mercado, pois, é definida como um sentimento de prazer ou desapontamento, em relação ao desempenho que se espera comparado a expectativa existente. Dessa forma, o valor que o cliente percebe sobre o produto ou serviço elevará ou não o grau de satisfação do cliente, ou seja, é quando os benefícios oferecidos sobressaem o valor da aquisição do produto ou serviço (COBRA, 2009).

De acordo com Rosa et al. (2017, p. 7), observa-se que "[...] a relação de valor é diretamente influenciada pela percepção da qualidade dos serviços oferecidos pelas organizações, e essa é a percepção que afeta o grau de satisfação do consumidor". Com as incertezas do mercado as organizações necessitam se adequar cada vez mais com as exigências das pessoas de modo a agregar valor aos produtos e serviços (ROSA et al. 2017).

Segundo Bentivegna (2002, p.80), "para um novo produto ou serviço ser bem-sucedido, ele tem que se difundir e ser adotado pelo público que busca atender". Ou seja, deve ser satisfatório na percepção dos usuários, principalmente por meios tecnológicos, em que as pessoas procuram opinar, discutir sobre os interesses comuns que possuem sobre determinado objeto em tempo real e de rápida propagação.

A usabilidade é determinada pela agilidade e simplicidade no seu uso, seja de um produto ou de um serviço. Os usuários preferem sistemas que sejam simples e intuitivos para atender suas necessidades de forma rápida e efetiva. Quanto mais complexo for o seu uso mais insatisfeito o usuário ficará e poderá não ter aceitabilidade no mercado, causando perda de ganho para a organização e até mesmo prejudicar a sua imagem (SILVA FILHO, 2010).

$\mathrm{O}$ autor ainda salienta que a interface do usuário com a usabilidade é um fator determinante para o sucesso organizacional, pois resulta no aumento do grau de eficiência com que o usuário executa suas tarefas, contribui para aumentar a fidelização do cliente com a empresa e reduz os custos de apoio ao usuário (SILVA FILHO, 2010).

Nielsen e Budiu (2014) ainda dizem que parte do segredo do sucesso e mais usabilidade dos aplicativos é devido a tendência de serem mais simples e mais fáceis na acessibilidade do que ao comparado com os sites. Os aplicativos móveis geralmente são mais simples o que contribui para uma melhor interação com o usuário.

No entanto os autores ainda salientam que "[...] os dispositivos móveis oferecem uma experiência do usuário empobrecida: telas minúsculas, conectividade lenta, maior custo de interação..." (NIELSEN; BUDIU, 2014, p. 34).

As percepções sobre a usabilidade e a facilidade de ferramenta é adquirida pela funcionalidade e a experiência individual com a tecnologia, como salientado por Dishaw e Strong (1999), e por isso ao aumentar a experiência sobre determinada ferramenta implicará no aumento da facilidade em usá-la e contribuir para a ascensão organizacional (BOBSIN; VISENTINI; LÖBLER, 2010).

A seguir, são salientados a experiência dos usuários e a sua contribuição para o desenvolvimento organizacional. 


\section{EXPERIÊNCIA DO USUÁRIO COM O USO DA TECNOLOGIA}

As mudanças tecnológicas e das inovações evoluíram rapidamente ao passar dos anos, principalmente no âmbito organizacional, e ainda há contínuas mudanças que impactam direta e indiretamente na economia global. Com isso entender, aprender e adaptar a essas mudanças é primordial para sobreviver e ainda se sobressair em relação aos adversários ao criarem e inovarem. (CORSATTO; HOFFMANN, 2016)

Para Marcos Cobra (2009, p.90), "a mente humana é a caixa postal das emoções. Ali estão registradas suas alegrias, tristezas e indiferenças em relação a diferentes experiências com produtos e serviços de diversas marcas". Portanto, pode-se dizer que as percepções por meio das experiências das pessoas ao longo do tempo afetam profundamente na tomada de decisões.

Sanz Casado (1994 apud ROZADOS; PIFFER, 2009) relata que as aplicações de estudos dos usuários servem para conhecer os hábitos e as necessidades de informações dos usuários, assim como avaliar os recursos das unidades de informação, medir a eficácia das unidades de informação, adequar o espaço, conhecer as necessidades da comunidade científica próxima e segmentar o mercado.

Lopes (2012, p. 4) descreve ainda que se a experiência do usuário está relacionada com as pessoas e os serviços digitais, é neste ponto que está determinada sua importância “"...] pois a interação implica na escolha do serviço que uma pessoa irá utilizar, qual lhe oferecerá o melhor benefício ou possibilidades". Desse modo, o usuário procurará o serviço ao qual obteve maior sensação de resolução dos seus problemas ou dúvidas.

Pode-se dizer que entender as necessidades dos usuários é a melhor forma de propiciar qualidade e satisfação dos usuários nos serviços prestados. "A percepção e experiência humana têm sido fatores determinantes na hora da escolha por um produto ou serviço" (SILVA FILHO, 2010, p.7).

Em razão à Experiência do Usuário, Silva Filho (2010, p. 7) ainda afirma que

[...] o sucesso de novos produtos não depende apenas dos esforços das equipes de propaganda e marketing, mas da inovação que as empresas colocam em seus produtos (preocupadas com seus usuários - clientes) e, principalmente, pela maneira através da qual os usuários (clientes) vêm os produtos (SILVA FILHO, 2010, p.7).

Araújo (2014, p. 33) contribui ao dizer que "a experiência do usuário pode gerar uma melhor aceitabilidade, tornando o produto mais bem-sucedido". Assim, ao compreender as interpretações percebidas, juntamente com a interação do produto ou serviço possam atender as expectativas das organizações e dos usuários.

Segundo Araújo (2014, pp. 33-34), "durante o desenvolvimento, conhecer o usuário e o consumidor pode auxiliar na escolha das melhores alternativas de projeto, principalmente em suas fases iniciais [...]", pois neste momento é onde os custos são reduzidos ao buscar soluções. Dessa forma a avaliação da Experiência do Usuário, serve para entender melhor a interação dos usuários com o produto e/ou serviço, de modo a entender as suas reais necessidades, através de métodos quantitativos e qualitativos o grau de experiência dos usuários em relação a utilidade dos produtos/ serviços.

$\mathrm{Na}$ experiência do usuário, ainda pode-se falar em avaliação da interação do usuário com os produtos e serviços da organização para que consiga identificar se as necessidades dos usuários foram atendidas ou se há problemas por meio da interação ou da usabilidade, manejando as deficiências ou oportunidades que surgirem de acordo com os objetivos organizacionais (PRATES; SOUZA, 2002). 
Para conhecimento contínuo de melhorias no atendimento dos consumidores é necessário que haja a identificação das experiências que os usuários têm, além de como está sendo construída a interação, a usabilidade e utilidade dos produtos e serviços, objetivando o aperfeiçoamento em um ambiente de concorrência acirrada e com consumidores cada vez mais exigentes (LOPES, 2012).

\section{PROCEDIMENTOS METODOLÓGICOS}

O método utilizado para a elaboração desta pesquisa foi o estudo de caso, pois busca entender um fenômeno complexo de acordo com o contexto em que está inserido, objetivando explorar situações da vida real, dentre outros aspectos. Com isso, "o estudo de caso consiste em coletar e analisar informações sobre determinado indivíduo, uma família, um grupo ou uma comunidade, a fim de estudar aspectos variados de sua vida" (PRODANOV; FREITAS, 2013, p. 60).

A metodologia adotada foi o qualitativo, pois, conforme Prodanov e Freitas (2013), interpreta o fenômeno e suas interações e busca entender e realizar descobertas nas pesquisas de campo, devido ao aprofundamento sobre o assunto. O tipo de pesquisa adotado neste trabalho é a exploratória devido a sua visão ampla sobre o objeto de pesquisa e a possível descoberta de lacunas, e por isso tem o objetivo de facilitar "[...] a delimitação do tema da pesquisa; orientar a fixação dos objetivos e a formulação das hipóteses ou descobrir um novo tipo de enfoque para o assunto". (PRODANOV; FREITAS, 2013, pp.51-52).

O objeto desta pesquisa foi uma empresa de grande porte do setor varejista localizada em Rondonópolis - MT. No entanto a empresa não autorizou divulgação de seu nome nesta pesquisa, sendo assim a empresa foi denominada como "Beta", com o intuito de que sua imagem não seja exposta.

O motivo a ter sido escolhido a empresa "Beta" foi pela conveniência e ser uma empresa implantada há vários anos e até mesmo estar consolidada na cidade de Rondonópolis - MT.

A população deste estudo foi de 384 clientes, contudo a amostra atingida foi de 110 respondentes para que assim conseguisse realizar o tratamento e a análise dos dados no intuito de atingir o objetivo da pesquisa com dados mais próximos com o público geral (OLIVEIRA; GRÁCIO, 2005).

Em razão do tamanho da amostra buscou-se atingir o total de respondentes por meio de um questionário eletrônico com perguntas fechadas e abertas para obter os dados necessários para a análise por meio de análise descritiva e de conteúdo, em que estas análises nos permitem discussões que gerem o aprofundamento na compreensão dos resultados com os objetivos propostos da pesquisa em conjunção com os levantamentos teóricos contribuindo assim para estudos futuros e agregação de valor para a sociedade" (PRODANOV; FREITAS, 2013).

De acordo com Kozinets (2014, pp. 61-62), a definição de netnografia é:

pesquisa observacional participante baseada em trabalho de campo online. Ela usa comunicações mediadas por computador como fonte de dados para chegar à compreensão e à representação etnográfica de um fenômeno cultural ou comunal (KOZINETS, 2014, pp. 61-62).

Ainda, segundo Kozinets (2014), a netnografia parte além dos estudos de face a face que comporta a etnografia, o que seria para o estudo das interações sociais com dados coletados em comunidades onlines. A partir da técnica netnográfica, foi possível realizar o levantamento dos dados da página no Facebook com localidade em Rondonópolis, para ser mais específico, utilizando os comentários dos clientes. Posteriormente, ao se analisar os dados foram nomeados 
como usuários de 1 a 13 como forma de manter o sigilo dos clientes identificados para que não tenham suas imagens expostas e categorizar cada um de acordo com cada problema descrito.

O passo-a-passo desta pesquisa obedeceu ao desenho a seguir conforme Figura 1.

Figura 1: Desenho da pesquisa

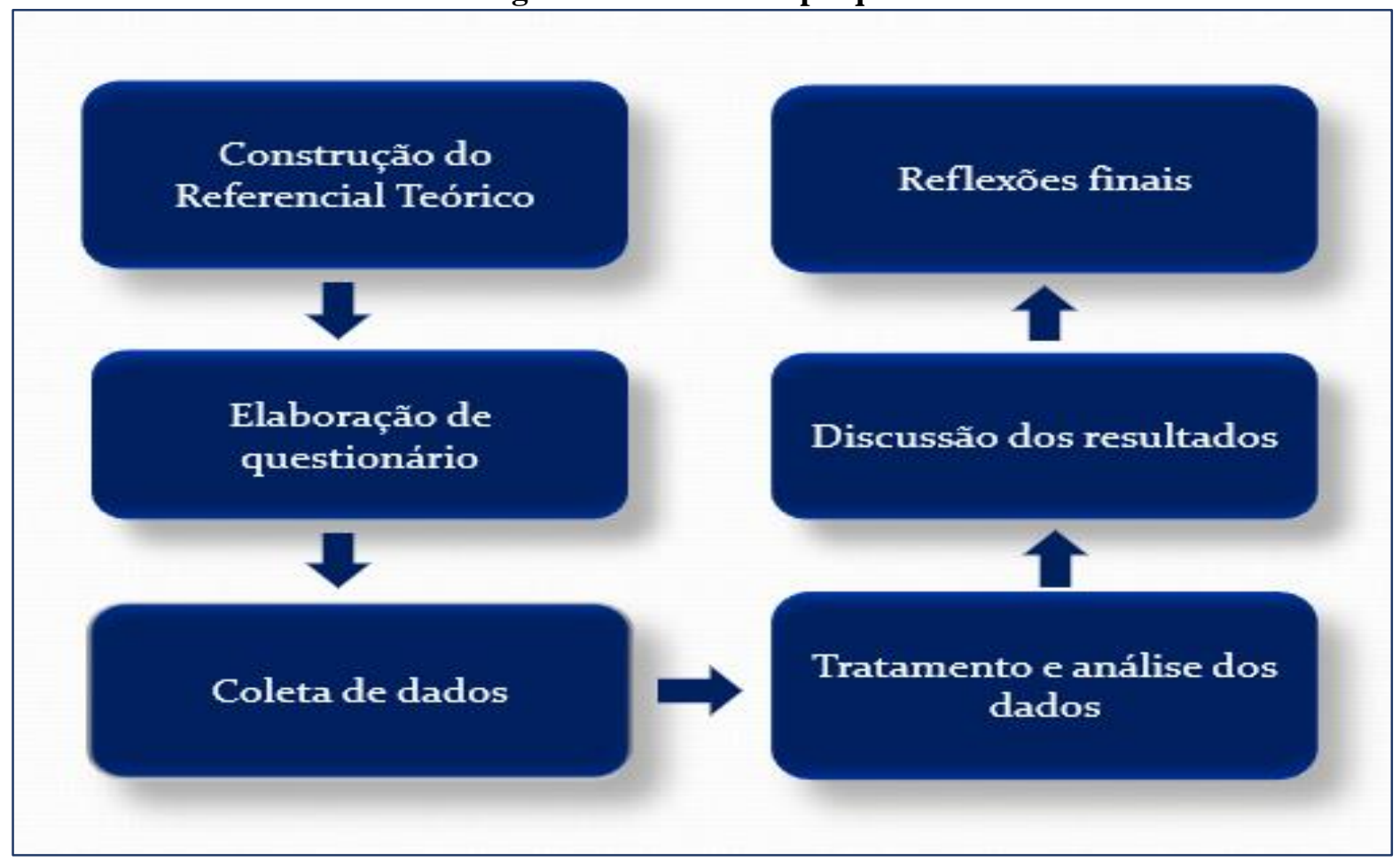

Fonte: Dados da pesquisa, 2018

\section{TRATAMENTO E ANÁLISE DOS RESULTADOS}

O aplicativo do cartão da empresa estudada tem como finalidade fornecer informações e funções que antes eram executados somente fisicamente e que com sua implantação foram disponibilizadas de modo online para minimizar as operações centralizadas na organização, além de, mais agilidade e comodidade nas informações. As funções são: Demonstrativo de faturas, visualização de limites de compra, bloqueio temporário do cartão, antecipação de parcelas, alteração de vencimento, alteração de limite, entre outros.

Os dados obtidos por meio do questionário eletrônico foram de 110 respondentes que possuem o crediário da empresa pesquisada, para que pudesse atingir o objetivo deste trabalho ao focar nos clientes que já tinham um contato com a empresa.

No perfil demográfico dos clientes abordados identificou-se que possuem entre 18 e 67 anos. Sendo 61 dos clientes com idades de 18 até 28 anos; 32 clientes, com 29 a 40 anos e 17 respondentes acima de 41 anos. O público atingido foi, de 76 mulheres $(69,10 \%)$ e 34 homens $(30,90 \%)$. Quanto ao nível de escolaridade, $13,6 \%$ cursaram o nível fundamental, 38,3\% o ensino médio, $33,6 \%$ o ensino superior incompleto e $14,5 \%$ possuem o ensino superior completo. Em relação a renda pessoal, $4(3,6 \%)$ não possuem nenhuma renda, $59(53,6 \%)$ até 1 salário, $40(36,4 \%)$ de 2 a 4 salários, $6(5,5 \%)$ de 5 a 8 salários e $1(0,9 \%)$ acima de 9 salários. $\mathrm{Na}$ preferência de pagamento das compras foram citados respectivamente: $\left(1^{\circ}\right)$ dinheiro, $\left(2^{\circ}\right)$ cartão de débito e $\left(3^{\circ}\right)$ de crédito que mais se destacaram, sendo seguidos pelo $\left(4^{\circ}\right)$ crediário. 
Em resumo pode se dizer que as mulheres jovens, com ensino médio e renda de até um salário são os usuários mais expressivos que usam o aplicativo. Existe também um percentual expressivo de clientes que estão cursando o ensino superior e que ganham de 2 a 4 salários.

Quando questionados sobre a facilidade de utilização de aplicativos apenas 3 responderam que não utilizam (2,7\%) e 107 utilizam (97,3\%). Deste modo foi utilizado somente os 107 respondentes para saber quantos realmente utilizavam o aplicativo de cartão da empresa, dos quais 75 dos clientes abordados $(69,8 \%)$ utilizam e 32 clientes $(30,2 \%)$ não utilizam.

No Gráfico 1 são demonstrados alguns parâmetros que os clientes buscavam ao acessarem o aplicativo, com isso percebeu-se que cerca de 39 dos clientes necessitam de rapidez nas informações juntamente com a facilidade do uso em que totalizou 38 dos clientes, seguidos do ganho de tempo com 29 clientes, e, por fim, a comodidade com que podem buscar as informações que precisam a qualquer momento em tempo real.

Gráfico 1: Parâmetros para utilização do aplicativo.

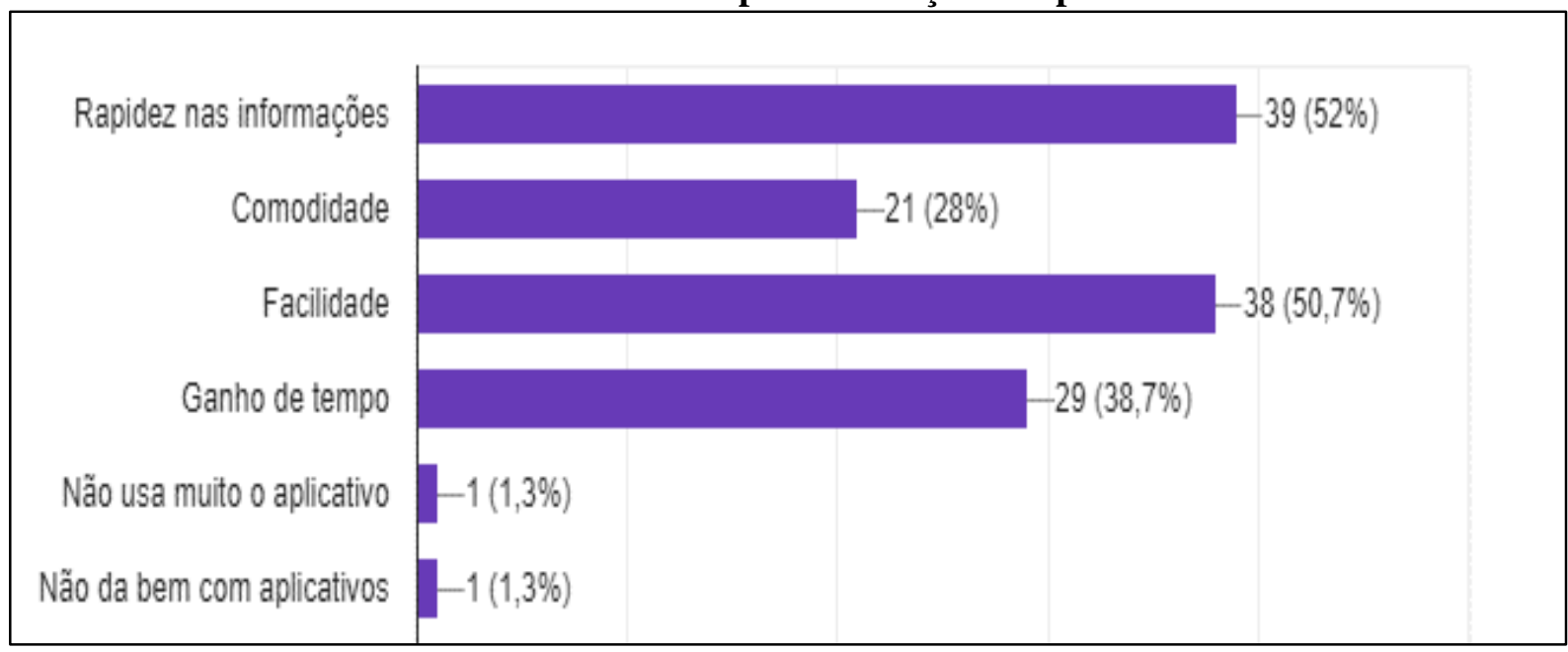

Desse modo, pode-se dizer que ao interagirem com os aplicativos as pessoas buscam algo que seja simples, de fácil acesso e atenda às suas expectativas de forma rápida e que não atrapalhe a sua rotina e sim que possa agilizar os seus processos para que tenha tempo de realizar outras tarefas ou até mesmo obter um tempo livre.

Dentre as 76 respostas obtidas, quando questionados sobre se o aplicativo atende necessidades dos clientes, $70,6 \%$ dizem que sim, $24 \%$ dizem que somente às vezes e $5,4 \%$ que não atende às necessidades. $\mathrm{O}$ que pode se observar é que mesmo a maioria dos clientes respondendo que atende às suas necessidades, existe um percentual expressivo de clientes que dizem que às vezes tem suas expectativas atendidas, isso pode ser um problema no uso do aplicativo que se não for tratado o quanto antes poderá acarretar em perdas para a empresa, assim como frustração por partes dos clientes, contribuindo para o aumento de insatisfações e até mesmo perdas futuras.

No Gráfico 2 constam as dificuldades que os clientes enfrentam ao usar o aplicativo. Foram identificadas 7 dificuldades, sendo estas nomeadas de D1 a D9. Dessa forma as definições utilizadas foram: D1= Lentidão, D2= Confuso, D3= Excesso de informações, D4= Não atende minhas necessidades, D5= Necessidade de demonstração de como utilizar o aplicativo, D6= Bloqueio e D7= Erro. 
Gráfico 2: Dificuldades encontradas no aplicativo.

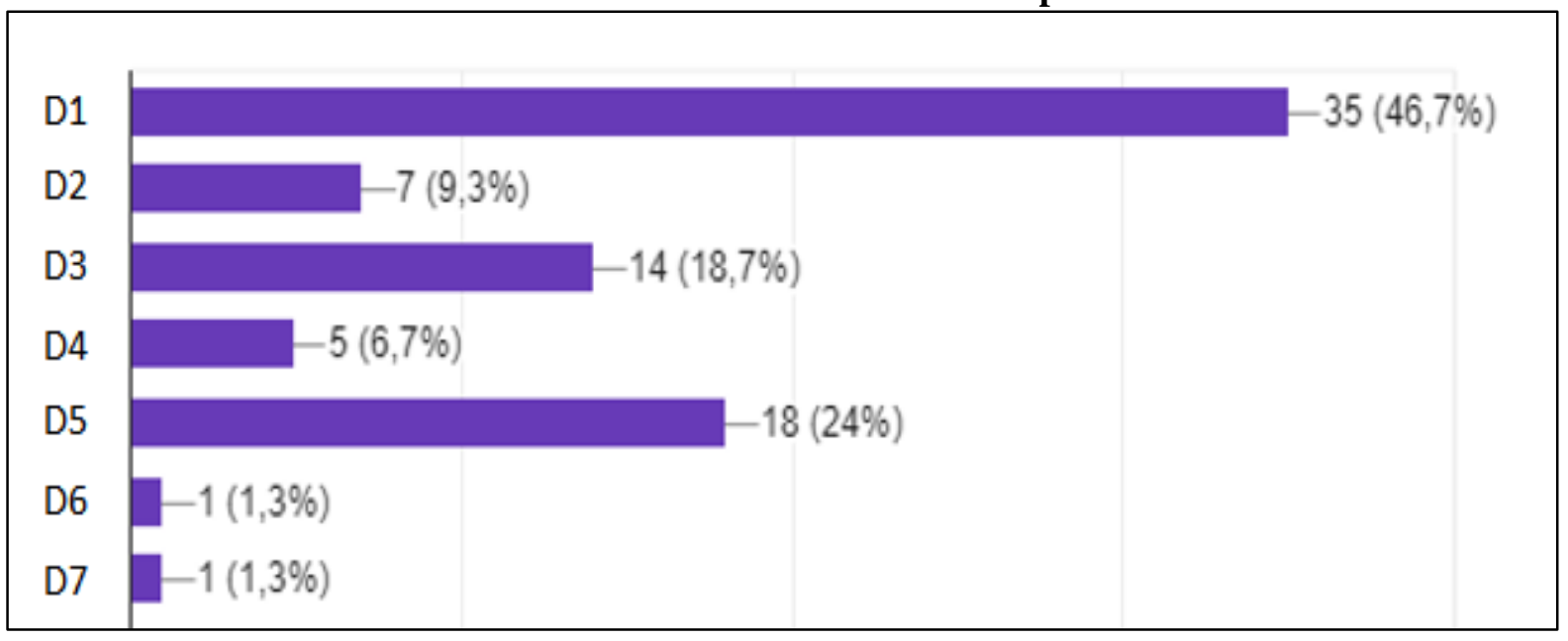

Fonte: dados da pesquisa, 2018.

Após a identificação das dificuldades percebeu-se que, a maior parte do público alcançado citou a D1, D3 e D5, ou seja, 46,7\% dos clientes disseram que o aplicativo é lento, $24 \%$ que o aplicativo necessita de uma demonstração de como utilizar e com $18,7 \%$ que possui excesso de informações. Esses dados, contribuem para o atingimento de um dos objetivos específicos desta pesquisa que é o de propor um tutorial de utilização do aplicativo do cartão para os clientes, pois, é um percentual de certo modo expressivo e que pode indicar uma falha no layout do aplicativo de modo que torna dificultoso o seu uso.

Outro ponto a se citar é, o percentual de respondentes que determinaram como dificuldade a lentidão no acesso, isso de certa forma leva a insatisfações dos usuários e fere alguns dos objetivos que os levam ao uso dos aplicativos como a rapidez das informações, a facilidade e o ganho de tempo. Sendo a rapidez com $21,33 \%$ um dos pontos a serem considerados para melhoria do aplicativo.

Conforme Gráfico 3 foram identificados quais seriam as sugestões dos clientes para que houvesse uma melhora no uso dos aplicativos. Após isso percebeu-se que há uma ênfase em se sugerir que o aplicativo seja mais rápido, o que nos leva a pensar que é um dos pontos fracos ao desenvolver o aplicativo que o torna lento e que se voltassem as suas atenções para torná-lo mais rápido obteriam resultados mais positivos.

Esse Gráfico 3 está ligado também diretamente com as dificuldades encontradas pelos clientes, sendo a mais enfatizada a lentidão ao usarem o aplicativo e a necessidade de simplificação e facilidade no acesso. 


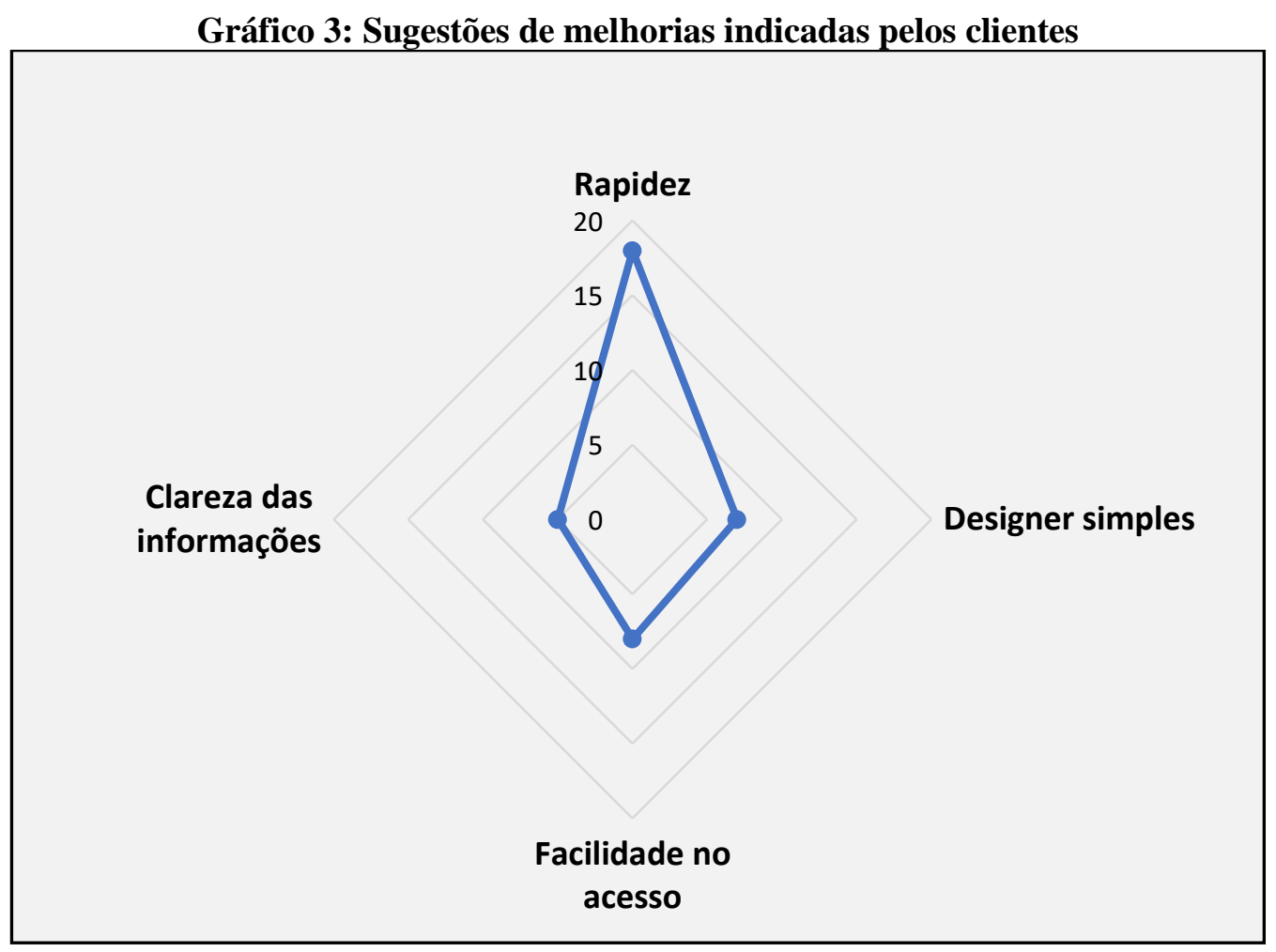

Fonte: dados da pesquisa, 2018.

No Quadro 1, foi realizado uma categorização em que as dificuldades selecionadas foram: lentidão, mal funcionamento, orientação, bloqueio e apresentação de erro. Assim foram utilizados os comentários encontrados na página do Facebook local da empresa por meio da técnica Netnográfica. O período de análise foi desde a sua implementação em 2016 até setembro de 2018, com isso analisou-se o comportamento digital mediante a experiência dos usuários. Para tal, as palavras chaves que foram utilizadas foram: aplicativo e app. Após isso foram divididos em 5 categorias como demonstrado no quadro a seguir.

Ao observar os dados do Quadro 1, percebe-se que as dificuldades na utilidade do aplicativo do cartão podem estar relacionadas com problemas no sistema informacional da empresa ou até mesmo com o seu design. Os clientes tendem a ter uma boa experiência quando se sentem bem ao acessarem, de modo a suprir as suas necessidades. No entanto foram identificadas 13 experiências ruins que os clientes se depararam no acesso e que foram divulgadas na Web e pode ser vista e compartilhada a qualquer momento, de modo a multiplicar as experiências negativas para outras pessoas. Isto nos leva a pensar que o aplicativo poderia ser mais simples e de fácil acesso para que não desistam inicialmente por não conseguirem sanar suas dúvidas. Outro ponto a se destacar é a facilidade no acesso às informações contidas no aplicativo melhorando assim sua eficiência. 
Quadro 1: Categorização dos dados encontrados na página do Facebook nos anos 2016 a 2018

\begin{tabular}{|c|c|}
\hline \multicolumn{2}{|c|}{ Dificuldades na utilização do aplicativo } \\
\hline Lentidão & $\begin{array}{l}\text { Usuário 3: "Por que o app do cartão de crédito está TÃO ruim? Há } \\
\text { tempos que não consigo acesso. Fica carregando um tempão, trava } \\
\text { o celular - tanto que preciso reiniciar - e não tenho acesso às } \\
\text { informações..." }\end{array}$ \\
\hline Mal funcionamento & $\begin{array}{l}\text { Usuário 4: "nao consigo ver o codigo de barras pelo app... Ja } \\
\text { atualizei e nao funciona..."; Usuário 9: " Não funciona o aplicativo..."; } \\
\text { Usuário 10: "não consigo entra no aplicativo..."; Usuário 12: "Eu } \\
\text { preciso ver a minha fatura do cartão ... To tentando no aplicativo e } \\
\text { não consigo..." }\end{array}$ \\
\hline Orientação & $\begin{array}{l}\text { Usuário 1: "Depois q eu fiz a ultima atualização do app não quer } \\
\text { abrir mais ..."; Usuário 5: "Preciso recuperar a senha do meu app, } \\
\text { ja solicitei e falam q vai enviar o código..."; Usuário 7: " desinstalei } \\
\text { do meu cel e instalei denovo ...e agora não consigo entrar ..." }\end{array}$ \\
\hline Bloqueio & $\begin{array}{l}\text { Usuário 2: "Estou tentando acessar o app mas não consigo diz que } \\
\text { o usuário está bloqueado , já tentei desbloquear e não consigo..."; } \\
\text { Usuário 6: tento entrar no aplicativo...da usuário bloqueado..."; } \\
\text { Usuário 13: "Não consigo mais entrar no aplicativo, fala que o } \\
\text { usuário tá bloqueado..." }\end{array}$ \\
\hline Apresentação de erro & $\begin{array}{l}\text { Usuário 8: "tento entrar e sempre da erro..."; Usuário 11: "não } \\
\text { estou conseguindo acessar pelo aplicativo, aparece uma } \\
\text { mensagem "conta não encontrada"..." }\end{array}$ \\
\hline
\end{tabular}

Fonte: Disponível em: <https://www.facebook.com/[Beta] -1308622382487885/?ref=br_rs>. Acesso em: 04/09/2018.

\section{CONCLUSÃO}

Os estudos da experiência do usuário são de valorosa contribuição na implementação desta pesquisa, pois ao entendermos as lacunas existentes poderá se pensar em soluções para os problemas enfrentados em busca da satisfação do usuário e consequentemente melhorias organizacionais.

Em face do exposto, tendo as problemáticas da empresa em relação especificamente ao aplicativo implantado, o tema escolhido para este estudo, tem como função entender as dificuldades e até mesmo insatisfações dos clientes em relação a eles. Assim uma melhor forma de compreensão é a análise das experiências dos usuários, contribuindo assim buscar melhorias que contribua para atender as expectativas, tanto dos usuários quanto da organização.

Assim pode concluir-se que as dificuldades encontradas pelos clientes são determinadas principalmente pela lentidão ao acessar o aplicativo de cartão e a necessidade de demonstração 
de como utilizar o aplicativo de forma rápida e simples atendendo assim as expectativas de ambos ao obterem processos operacionais de forma eficiente e objetiva.

Dessa forma ao propor um tutorial de como utilizar o aplicativo possa simplificar a interação do aplicativo com os clientes. Outra forma que nos leva a pensar que facilitará esta interação é a redução de informações redundantes, de forma a torná-lo mais "limpo" e consequentemente mais acessível. Isso tudo contribui na agregação de valor para a organização.

Como limitação da pesquisa se deve ao tempo, ainda mais em relação ao tamanho da amostra, que no primeiro momento foi estipulado para aplicação do questionário para 384 clientes, porém foi aplicado somente para 110 pessoas. Outra limitação fora os dados coletados dos clientes que podem não ter respondidos com toda a verdade precisa em que poderia enviesar os resultados. Para sugestão de estudos futuros firma-se a comparação entre duas ou mais empresas de grande porte que possuem aplicativos.

\section{REFERÊNCIAS}

AMARAL, Sueli Angélica do. Estudo de Usuário de e Marketing da Informação: User Study and Information Marketing. In: XIII Encontro Nacional de Pesquisa em Ciência da Informação. 2012. 20 p.

ARAUJO, Fernanda Steinbru ch. Avaliação da experiência do usuário: Uma proposta de sistematização para o processo de desenvolvimento de produtos. Universidade Federal de Santa Catarina: Florianópolis. 2014. 238 p.

BENTIVEGNA, Fernando Jucá. Fatores de impacto no sucesso do marketing boca a boa online. Revista de Administração de empresas: São Paulo. v. 42. N.1. Jan/mar. 2002. p. 79-87.

BOBSIN, D.; VISENTINI, M. S.; LÖBLER, M. L. A influência dos determinantes do trabalho gerencial na percepção do ajuste entre a tecnologia e a tarefa: um estudo exploratório. Revista Eletrônica de Sistemas de Informação, v. 9, n. 2, p. 1-25, 2010.

CIRIBELI, João Paulo; PAIVA, Victor Hugo Pereira. Redes e mídias sociais na internet: realidades e perspectivas de um mundo conectado. Belo Horizonte: Revista Mediação. v. 13. n. 12. Jan/jun, 2011.

COBRA, Marcos. Administração de marketing no Brasil. Rio de Janeiro: Elsevier. 3 ed. 2009. 428 p.

CORSATTO, C. A.; HOFFMANN, W. A. M. A Evolução das Mudanças Técnicas, Tecnológicas e da Inovação e seus Impactos na Produção do Conhecimento Organizacional: Aprendizagem Organizacional e Open User Innovation. Perspectivas em Gestão \& Conhecimento, v. 6, n. 2, p. 4-31, 2016.

Disponível em: https://www.facebook.com/Pernambucanas-1308622382487885/?ref=br_rs. Acesso em: 04/09/2018.

GOMES, C. M. R.; FARIAS, J. S. A influência da Expectativa de Desempenho e de Esforço Percebidas por Usuários no Uso de um Aplicativo de Compras. Contabilidade, Gestão e Governança, v. 20, n. 1, p. 72-90, 2017. 
KOTLER, Philip; KELLER, Kevin Lane. Administração de Marketing. São Paulo: Pearson Education do Brasil. 12 ed. 2012.

KOZINETS, Robert V. Netnografia: realizando pesquisa etnográfica online. Porto Alegre: Penso. 2014.

LOPES, Elisabete Cristina. Uma (Re)visão do conceito de experiência do usuário: a experiência como narrativa. USP: São Paulo. 2012. 42 p.

NIELSEN, Jakob; BUDIU, Raluca. Usabilidade Móvel. Rio de Janeiro: Elsevier. 1 ed. 2014.

OLIVEIRA, Ely Francina Tannuri de; GRACIO, Maria Claudia Cabrini. Análise a respeito do tamanho de amostras aleatórias simples: uma aplicação na área de Ciência da Informação. Revista de Ciência da Informação. v.6. n.3. Junho, 2005.

PRATES, Raquel Oliveira; SOUZA, C.S. Extensão do Teste de Comunicabilidade para Aplicações Multi-usuário. Cadernos do IME: v. 13. p.46-56, 2002.

PRODANOV, Cleber Cristiano; FREITAS, Ernani Cesar de. Metodologia do trabalho científico: métodos e técnicas da pesquisa e do trabalho acadêmico. Editora Freevale. RS: Novo Hamburgo. 2 ed. 2013.

ROSA, S. C.; SCHREIBER, D.; SCHMIDT, S.; KUHN JUNIOR, N. Management Practices that Combine Value Cocreation and User Experience: An Analysis of the Nubank Startup in the Brazilian Market. Revista de Gestão, Finanças e Contabilidade, v. 7, n. 2, p. 22-43, 2017.

ROZADOS, Helen Frota; PIFFER, Bárbara Pilatti. Pesquisa de Marketing e estudos de usuário: um paralelo entre os dois processos. Em questão: Porto Alegre, RS. vol. 15. núm. 2. jul/dez, 2009,
p.
169-182.
Disponível
em:

http://seer.ufrgs.br/index.php/EmQuestao/article/view/10387. Acesso em 29 de agosto de 2017.

SILVA FILHO, Antonio Mendes da. Conectividade e Informação - O mundo em suas mãos: Apple é sinônimo de Inovação orientada para 'User Experience'. Revista Espaço Acadêmico. n.109. jun. 2010. p. 7-11. Disponível em: http://periodicos.uem.br/ojs/index.php/EspacoAcademico/article/view/10062/5589. Acesso em: 28 de agosto de 2017.

SILVA FILHO, Antonio Mendes da. Inovação e Usabilidade orientada para 'User Experience'. Revista Espaço Acadêmico. n.110. jul. 2010. p. 69-72.

SIQUEIRA, N. S. C.; CHRISTINO, J. M. M. Análise do Mix de Marketing de Serviços de Transporte de Passageiros Através de Dispositivos Móveis no Brasil. Marketing \& Tourism Review, v. 2, n. 1, p. 1-34, 2017.

ZONATO, Anderson Nigro. O celular como ferramenta de comunicação integrada de Marketing. Inovcom. 2014. v. 6 n. 2. p. 16-26. 